\title{
Contested dominance modifies the anovulatory consequences of social subordination in female marmosets
}

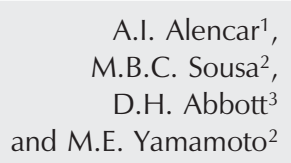

\author{
${ }^{1}$ Secretaria Municipal de Saúde, Natal, RN, Brasil \\ ${ }^{2}$ Departamento de Fisiologia, Universidade Federal do Rio Grande do Norte, \\ Natal, RN, Brasil \\ ${ }^{3}$ Department of Ob/Gyn and National Primate Research Center, \\ University of Wisconsin, Madison, WI, USA
}

\author{
Correspondence \\ M.E. Yamamoto \\ Departamento de Fisiologia, UFRN \\ Caixa Postal 1511 \\ 59072-970 Natal, RN \\ Brasil \\ Fax: +55-84-211-9206 \\ E-mail: emilia.yamamoto@uol.com.br
}

A.I. Alencar, M.B.C. Sousa and M.E. Yamamoto were supported by CNPq (Nos. 521186-97, 470601/

2003-5, and 524409/96, respectively), and D.H. Abbott was supported by NIH (Nos. RR000167 and MH60728), and NSF (No. IBN-9604321).

Received March 22, 2005

Accepted December 6, 2005

\begin{abstract}
Dominance status among female marmosets is reflected in agonistic behavior and ovarian function. Socially dominant females receive submissive behavior from subordinates, while exhibiting normal ovulatory function. Subordinate females, however, receive agonistic behavior from dominants, while exhibiting reduced or absent ovulatory function. Such disparity in female fertility is not absolute, and groups with two breeding females have been described. The data reported here were obtained from 8 female-female pairs of captive female marmosets, each housed with a single unrelated male. Pairs were classified into two groups: "uncontested" dominance (UD) and "contested" dominance (CD), with 4 pairs each. Dominant females in UD pairs showed significantly higher frequencies (4.1) of agonism (piloerection, attack and chasing) than their subordinates (0.36), and agonistic behaviors were overall more frequently displayed by $\mathrm{CD}$ than by UD pairs. Subordinates in CD pairs exhibited more agonistic behavior (2.9) than subordinates in UD pairs (0.36), which displayed significantly more submissive (6.97) behaviors than their dominants (0.35). The data suggest that there is more than one kind of dominance relationship between female common marmosets. Assessment of progesterone levels showed that while subordinates in UD pairs appeared to be anovulatory, the degree of ovulatory disruption in subordinates of $\mathrm{CD}$ pairs was more varied and less complete. We suggest that such variation in female-female social dominance relationships and the associated variation in the degree and reliability of fertility suppression may explain variations of the reproductive condition of free-living groups of common marmosets.
\end{abstract}

\section{Introduction}

Dominance and subordination reflect a relationship between two animals competing for food, mates, territories, or other resources. Dominance is normally associated
Key words - Callitrichids - Dominance

- Progesterone levels

- Agonistic behavior

- Marmosets 
may remain stable for long periods of time and through all kinds of competition, as observed in Cercopithecus aethiops (2), or may be unpredictable as in Papio anubis, because one animal may be dominant in some aspects but not in others (3). It has been suggested (4) that there may be different kinds of dominance - clear or uncontested dominance (UD) in which one individual is always dominant in relation to another, or contested dominance (CD) in which subordinate individuals submit, but disputes occasionally occur.

In callitrichids, females that receive submissive behavior from other females are considered to be dominant (Callithrix jacchus (5); Saguinus oedipus (6)). These dominant females are usually the only females in their social groups to exhibit circulating or excreted hormonal levels indicative of ovulatory ovarian cycles (S. fuscicollis (7), S. oedipus $(6,8)$ and $C$. jacchus $(5,9))$. These findings have suggested a close relationship between female dominance status and fertility in these non-human primates.

In most callitrichid groups, only one of the females produces offspring, but in captive family groups of $C$. jacchus, daughters of the reproductive female may cycle $(5,10)$ provided that they are not subordinate to their mothers (11). Although ovulatory, these latter females do not usually become pregnant and do not deliver term infants. The situation is somewhat analogous in captive groups of unrelated females, in which ovulatory cyclicity can be exhibited by the highest ranking subordinate (rank \#2) female while it is usually completely inhibited in lower ranking (ranks \#3 and \#4) subordinates (12).

Nevertheless, polygyny has been reported for the genus Callithrix. Daughters of dominant $C$. jacchus females living in captive families were able to conceive and give birth in their intact family groups (13), provided that the daughters were given access to an unrelated male for fertile copulations away from the family cage. There have been fur- ther reports of polygyny in captive (14) and wild- $C$. jacchus groups (15-17). In all reports of two-breeding female groups, close kin relations between the two reproductive females were known or at least suspected.

Which are the factors that allow suppression of fertility in subordinate females in some groups and favor polygyny in other groups of the same species? Some researchers $(18,19)$ suggest that polygyny could be tolerated by dominant females when dominant and subordinate females give birth far apart, avoiding competition for food and for caregivers. It has been suggested (20) that polygyny in Leontopithecus rosalia groups may increase the dominant female's inclusive fitness, especially when mother and daughter are the primary and secondary reproductive females in the same group. Could there be different kinds of dominance relationships between callitrichid females that have different consequences for subordinate female fertility?

To answer these questions we assessed aggressive and submissive behavior exhibited by pairs of female common marmosets, housed with an unrelated male to trigger female-female competition, in order to readily characterize dominance relationships between the pairs of females. We also assessed ovulatory function by routine collection of blood and fecal samples to determine pre- and post-ovulatory progesterone levels. As dominance relations are complex, their intensity and modulation depend on the dynamics of the agonistic behavior exhibited. We, therefore, expected that in pairs that continued competing for dominance, both females would present ovulatory progesterone profiles, and that they would display high levels of agonistic behavior until a clear dominant status was achieved by one of the females. In other pairs, where a UD relationship was rapidly established, we expected that only the behaviorally dominant female would exhibit a progesterone profile compatible with ovulation, and that levels of 
agonistic behavior would be lower than in female pairs of $\mathrm{CD}$.

\section{Material and Methods}

\section{Animals and experimental procedure}

The 16 adult female and 8 adult male common marmosets used in this study were housed at the Núcleo de Primatologia, Universidade Federal do Rio Grande do Norte (UFRN), in the Northeastern region of Brazil. Females were housed in 8 pairs in outdoor individual cages measuring $2 \times 2 \times 1 \mathrm{~m}$ under natural conditions of light, temperature and humidity. Animal management and nutrition were similar to those described elsewhere (21). All observation cages were equipped with one-way mirrors.

Each female-female pair was followed for 15 consecutive weeks in three weekly 30-min sessions, for a total observation of $22.5 \mathrm{~h}$ per pair. The 15 -week period was not completed for pair \#7 due to a fight that necessitated separating the females permanently. Pairs \#1, 3, 5, and 7 were twin sibs, pairs \#2 and 6 were mother and daughter and pairs \#4 and 8 were donated to our colony by IBAMA (Brazilian Forestry Department). They arrived as female-female pairs but there was no information on their relatedness. Eight males from our colony, unrelated and unknown to the females, were introduced to the pairs of females from the 6th week of the experiment, as described below. Since closely related female common marmosets $(\mathrm{N}=6$ in this study, UD pairs \#1, 2, 3, and CD pairs $\# 5,6$, and 7) can contend for dominance and can exhibit dominant-subordinate relationships in both wild- (22) and captive $(23,24)$ social groups, there were no expectations that pairs of closely related females would fail to exhibit qualitatively different dominant-subordinate relationships compared to pairs of unrelated females $(\mathrm{N}=2$ in this study, UD pair \#4 and CD pair \#8).

During the first 5-week observation pe- riod, the pairs of females were observed without the male. During the second 5-week period, one male (always the same for each pair) was introduced into each pair's cage during the observation period and was then removed. During the last 5-week period, the males were housed permanently in each of the female pairs' cages. The three successive 5-week observation periods were regarded as successive escalations in femalefemale sexual competition.

\section{Behavioral sampling}

We recorded all occurrences of three aggressive behaviors that we described as indicative of dominance: piloerection, attack and chasing. These behaviors are usually considered to be indicators of dominance. We also recorded all occurrences of behaviors indicative of subordination in 4 of the 8 pairs (pairs \#3, 4, 7, and 8) for each 5-week period: facial submission, leg stand and continuous submission. All recorded behaviors are described in Table 1. We used continuous focal sampling in all observations, using both females as the focal animals for each of two observers. The observers, with a minimum $85 \%$ coefficient of reliability, recorded behavioral frequencies on a check-sheet that were later transferred to computer files.

\section{Blood and feces sampling}

To monitor ovarian activity we collected blood from four female pairs (\#1, 2, 5, and 6) and feces from the remaining four (pairs \#3, 4,7 , and 8) twice weekly throughout the 15week period. This frequency of sampling allowed detection of the approximately 19to 20-day elevation of plasma or fecal progesterone levels in the post-ovulatory, luteal phase of the 28-day ovarian cycle of female common marmosets (25). Blood samples were withdrawn from the femoral vein between 9:00 and 10:00 h. After collection, the samples were centrifuged at 2,060 $g$ over a 
period of $10 \mathrm{~min}$ and frozen at $-20^{\circ} \mathrm{C}$ until they were assayed by enzyme immunoassay (EIA) for progesterone (26). In the remaining four pairs, we collected feces twice a week from undisturbed females in their cages between 12:00 and 15:00 h. During fecal sampling, we stayed close to a female's cage until she defecated. We then entered and collected the feces. Fecal samples were stored in small plastic tubes labeled with the identity of the animal, date and time of collection and frozen at $-20^{\circ} \mathrm{C}$. Before running the EIA for progesterone, steroid hormones were extracted from the fecal material by hydrolysis and solvolysis, as described previously (27). The methodological difference in progesterone measurement (blood and feces) between pairs of females derives from the validation of a new method (27) at the time of the complementary data collection, compatible with blood assays, which was less invasive and less stressful for the animals.

\section{Hormone assays}

Blood samples from two pairs (\#1 and
\#2) were analyzed in the Assay Services Laboratories of the National Primate Research Center at the University of Wisconsin, Madison, WI, USA (WPRC). The concentrations of plasma progesterone were determined using an EIA (28). The monoclonal antibody (R4866) was obtained from Coralie Munro (University of California, Davies, CA, USA) and the sensitivity was $0.01 \mathrm{ng} / \mathrm{mL}$. The standards were prepared using progesterone (99\%, Sigma). Crossreactivity for 20ß-hydroxyprogesterone was 2.5 and 7.0 for pregnanediol, whereas for $17 \alpha$-hydroxyprogesterone, $11 \alpha$-hydroxyprogesterone, pregnenolone, androstenedione, 17ß-estradiol, cortisol and testosterone was $<0.1$. Intra-assay coefficients of variation (CV) for low- and high-concentration plasma pools were 15.7 and $11.5 \%(\mathrm{~N}=10)$, respectively. The other blood samples were assayed in the laboratory of hormonal assays of Universidade Federal do Rio Grande do Norte (UFRN). Inter- and intra-assay CV were 18.0 and $10.0 \%(\mathrm{~N}=10)$ respectively. There were no differences $(\mathrm{P}>0.05)$ between follicular or luteal phase progesterone

Table 1. Definitions of the behavioral patterns used in this study.

\begin{tabular}{|c|c|}
\hline Behavioral patterns & Definition \\
\hline \multicolumn{2}{|l|}{ Dominance } \\
\hline Piloerection & $\begin{array}{l}\text { Body pelage is fully erected accompanied by a conical erection of tail pelage. We } \\
\text { recorded one occurrence each time one female erected and flattened the pelage, } \\
\text { regardless of duration. Piloerection was recorded only when observed out of the } \\
\text { context of attack and chasing. }\end{array}$ \\
\hline Attack & $\begin{array}{l}\text { Focal animal grapples aggressively with the partner. This behavior involves biting, } \\
\text { clawing and wrestling (31). We recorded one occurrence each time two females } \\
\text { presented any of the behaviors above, until physical contact was broken for at } \\
\text { least } 10 \mathrm{~s} \text {. }\end{array}$ \\
\hline Chasing & $\begin{array}{l}\text { Focal animal follows and chases away another one in the cage. The chasing } \\
\text { animal may present piloerection. We recorded one occurrence for each bout until } \\
\text { chasing was discontinued. }\end{array}$ \\
\hline \multicolumn{2}{|l|}{ Subordination } \\
\hline Facial submission & $\begin{array}{l}\text { Tufts flattened (lower ear tufts against the side of the head) and/or facial grimace } \\
\text { (mouth partially open, exposing the teeth). }\end{array}$ \\
\hline Leg stand & The animal stands on its hind legs and stares in a fixed direction for a few seconds. \\
\hline Continuous submission & $\begin{array}{l}\text { The animal cringes and places its tail between its legs, usually positioned below } \\
\text { the other animals in the cage. }\end{array}$ \\
\hline
\end{tabular}


values determined at either WPRC or UFRN. Fecal samples were also analyzed as described previously $(27,29)$ at UFRN and inter- and intra-assay CV were $19.6(\mathrm{~N}=10)$ and $4.4 \%(\mathrm{~N}=10)$, respectively.

An index of ovulatory function for each female provided the basis for calculating a ratio for ovulatory function for each dominant and subordinate pair. This index was based on the profile of progesterone concentrations in plasma or feces during the three experimental periods for each female. The index was determined as: 1) complete absence of progesterone elevations; 2) irregular increases in progesterone concentrations, plasma values $>10 \mathrm{ng} / \mathrm{mL}$ or fecal values higher than three times the baseline values during the follicular phase or $100 \mathrm{ng} / \mathrm{g}$, and 3 ) regular ovulatory cycles with luteal phase length typical of normal cycles for common marmosets. Females were considered to have ovulated on the day prior to a sustained (consecutive blood samples) increase in plasma progesterone levels above $10 \mathrm{ng} / \mathrm{mL}$ (30) or 2 to 4 days prior to a sustained increase in fecal progesterone of at least 1.5 times the mean of the preceding baseline values of the follicular phase (30). Following ovulation, they were considered to be in the luteal phase of an ovulatory cycle, or pregnant, until plasma progesterone fell to the levels recorded before ovulation, characterizing a following follicular phase which lasted until progesterone concentrations rose again (30). Thus, we operationally defined the irregular cycles as exhibiting more than 13 days between ovulatory cycles $(10,31)$ during which plasma progesterone levels remained low between two successive luteal phases.

\section{Statistical analysis}

Repeated measures MANOVA followed by the post hoc Tukey test was used to analyze the differences between groups and between dominant and subordinate females.
The factors tested were rank (dominant or subordinate), group (UD and CD) and period (male absent, male present and male resident). Correlations between behavioral and hormonal data were calculated using the Pearson moment-product test.

\section{Results}

In all cases, dominant females were considered to be the females exhibiting higher frequencies of dominant behaviors (Table 2). In each pair, during each 5 -week period, dominant females were identified from their higher frequency of dominant behaviors (Table 2). There were, however, differences in the extent to which dominant females exceeded subordinates in the display of dominant behaviors. To qualify the associated characteristics of such differences, we classified the pairs into two groups: UD (pairs 14) in which one female (the dominant female) exhibited dominant behaviors at least at three times the frequency of the other (the subordinate), and CD (pairs 5-8) in which one female (the nominal dominant female) displayed dominant behaviors at only 1.11.5 times the rate displayed by the other female (the nominal subordinate; Table 2).

Table 2. Dominance ranking based on behavioral and hormonal measures.

\begin{tabular}{lccc}
\hline Pair & $\begin{array}{c}\text { Dominance } \\
\text { behaviors } \\
\text { (Dom/Sub ratio) }\end{array}$ & $\begin{array}{c}\text { Submissive } \\
\text { behaviors } \\
\text { (Sub/Dom ratio) }\end{array}$ & $\begin{array}{c}\text { Ratio of } \\
\text { ovulatory } \\
\text { index }\end{array}$ \\
\hline Uncontested dominance & & & \\
1 & $3.0(1.5 / 0.5)$ & - & $3.0(3.0 / 1.0)$ \\
2 & $30.0(3.0 / 0.1)$ & - & $2.0(2.67 / 1.33)$ \\
3 & $12.8(6.4 / 0.5)$ & $17.0(3.4 / 0.2)$ & $2.6(3.0 / 1.33)$ \\
4 & $13.0(5.2 / 0.4)$ & $53.0(5.3 / 0.1)$ & $2.6(3.0 / 1.33)$ \\
Contested dominance & & & $1.0(1.0 / 1.0)$ \\
5 & $1.1(3.5 / 3.1)$ & - & $1.1(3.0 / 2.67)$ \\
6 & $1.3(4.0 / 3.2)$ & - & $2.0(2.67 / 1.33)$ \\
7 & $1.5(2.5 / 1.7)$ & $1.0(0.2 / 0.2)$ & $1.5(2.0 / 1.33)$ \\
8 & $1.5(2.7 / 1.8)$ & $0.6(0.7 / 1.1)$ &
\end{tabular}

The ratio for the ovulatory index between each dominant (Dom) and subordinate (Sub) female (determined by progesterone concentrations in plasma or feces) varied from 3 (regular ovulation) to 1 (no ovulation) during the three 5-week study periods. 
These grouping differences were maintained during all three 5-week periods (MANOVA, $\left.\mathrm{F}_{(1,44)}=5.343, \mathrm{P}=0.026\right)$. There were, nevertheless, no significant differences between the frequencies of given dominant behaviors displayed by dominant females between $\mathrm{CD}$ and UD groups (Tukey, $\mathrm{P}=0.945$ ). In contrast, the frequencies of dominant behaviors displayed by subordinate females in UD were significantly lower than those displayed by subordinates in $\mathrm{CD}$ (Tukey, $\mathrm{P}=0.007$ ) and by dominants in UD (Tukey, $\mathrm{P}=0.047$ ) (Figure 1A). Submissive behaviors were frequently displayed by subordinate females
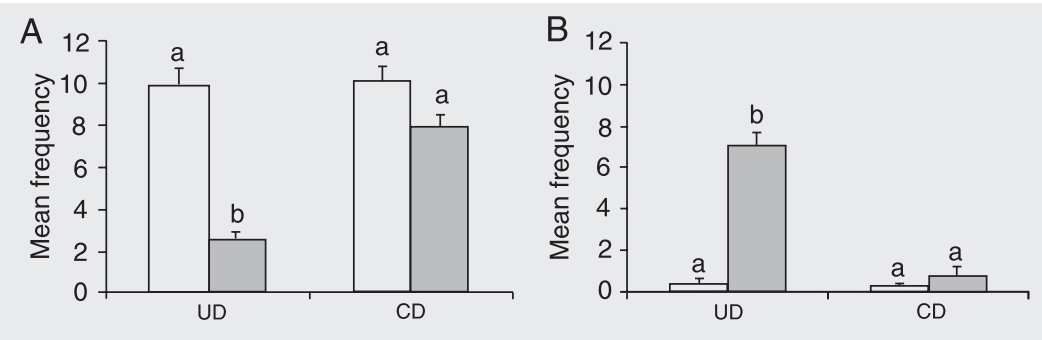

Figure 1. Frequency of behaviors indicative of dominance given $(A, N=8)$ and subordination given ( $B, N=4)$ in Callithrix jacchus female pairs in the uncontested dominance (UD) and contested dominance (CD) groups. Data are reported as means \pm SEM and the means were calculated using the data of the whole duration of the experiment (15 weeks). Open columns indicate dominant females and filled columns subordinate females. Different letters above the columns represent statistically significant differences $(P<0.05$, Tukey test).
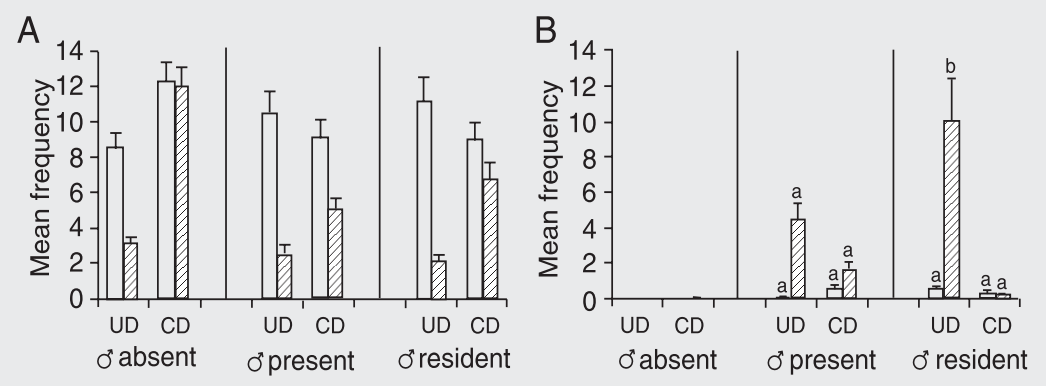

Figure 2. Frequency of behaviors indicative of dominant $(A, N=8)$ and submissive $(B, N=4)$ behaviors in Callithrix jacchus female pairs in uncontested dominance (UD) and contested dominance $(C D)$ groups during each of the three 5-week study periods (period 1 - male absent; period 2 - male present; period 3 - male resident). Data are reported as means \pm SEM. The straight lines indicate the end of a 5-week period and the beginning of the next. Open columns indicate dominant females and shaded columns subordinate females. Different letters above the columns represent statistically significant differences $(P<0.05$, Tukey test). from UD only. These frequencies were significantly different from those of all other females MANOVAF $_{(1,20)}=4.408, \mathrm{P}=0.049$; Tukey: UD dominant, $\mathrm{P}=0.022 ; \mathrm{CD}$ dominant, $\mathrm{P}=0.0278 ; \mathrm{CD}$ subordinate, $\mathrm{P}=0.044$ (Figure 1B).

An analysis of dominant and submissive behaviors during each of the three 5-week periods shows that the presence of an unrelated male, even temporary, had an influence on the females. In CD, dominance behaviors were similar for both females during the three periods but in UD the dominant females displayed dominant behaviors more frequently than the subordinate females in the absence (period 1), in the presence (period 2) and during residence (period 3) of a male (Figure 2A). These differences were not statistically significant possibly due to the low sample size (statistics in Table 3, lines 1-4), but they showed consistent trends for dominant and subordinate females in each group. Submissive behaviors were not displayed in the absence of the male in either group. During period 3, when the male was living with the pair, UD subordinates displayed submissive behaviors significantly more than their dominant counterparts, and than dominant and subordinate females from CD pairs (Table 3, lines 5-8). CD dominant and subordinate females displayed submissive behaviors rarely and at similar frequencies during all 5-week periods (Table 3 , lines 9-12) (Figure 2B). Males, on the other hand, did not treat dominant and subordinate females very differently. They directed the same amounts of afilliative (Table 3, lines 13-15) and sexual behavior to both females during periods 2 and 3 (Table 3, lines 1618).

The dominance behavior ratios of UD female pairs show that dominant females displayed up to 30 times, and at least 3 times, more agonistic behaviors than their subordinate partners and, in the two pairs for which we recorded submissive behaviors, subordinate females displayed 53 and 17 times more 
submissive behaviors than dominant females. In $\mathrm{CD}$, in contrast, dominant and subordinate females displayed very similar rates of dominant and submissive behaviors, with all ratios close to 1 (dominance behavior ratios varying from 1.1 to 1.5 and submissive behavior ratios varying from 0.6 and 1.0; Table 2).

Female pairs from UD and CD also differed in their hormonal profiles. In UD, only the dominant females displayed progesterone levels indicative of ovulatory cycles during the three 5-week periods, while subordinate females showed varying levels of inhibition of ovulatory cycles. All UD dominant females became pregnant eventually. Dominant females of pairs 1 and 2 became pregnant during the experiment (see sustained levels of progesterone during male residence, period 3). The other two UD dominant females became pregnant and gave birth after the end of the experiment. In $\mathrm{CD}$, both dominant and subordinate females showed similar progesterone levels during at least one of the three 5-week periods (Figure 3). In pair 5, both females were inhibited; in pair 6 , both females ovulated simultaneously twice, and then the subordinate became inhibited; in pair 7, both females ovulated, and in pair 8 , both showed one ovulation cycle and subsequently both failed to ovulate. Accordingly, ovarian functioning ratios between dominant and subordinate females varied from 1.0 to 2.0 in $\mathrm{CD}$ and from 2.0 to 3.0 in UD (Table 2). All CD dominant females also got pregnant, all of them after the end of the observations. Two females (pairs 5 and 6) gave birth only after the removal of the subordinate females.

Correlations between dominance and submissive behaviors and progesterone levels yielded no significant results regarding dominant or subordinate females in either group (Pearson, dominants UD, $\mathrm{r}^{2}=0.1286, \mathrm{P}=$ 0.173 ; dominants $\mathrm{CD}, \mathrm{r}^{2}=-0.1282, \mathrm{P}=$ 0.172 ; subordinates UD, $\mathrm{r}^{2}=-0.0152, \mathrm{P}=$ 0.872 ; subordinates $\mathrm{CD}, \mathrm{r}^{2}=-0.0354 \mathrm{P}=$ $0.707)$.
By the end of the observation period, and sometimes after that, we had to remove subordinate females from the pairs (two CD pairs, 6 and 8), because of an escalation of aggression from the dominant female. In these two cases this was accompanied by changes in progesterone levels indicative of anovulation in one of the females of the pair, suggesting that the dominance relation had changed.

In one of the pairs (pair 7) there was a probable infanticide, as the first set of twins of the dominant female was found dead with clear signs of injuries caused by conspecifics, although we were not able to ascertain who the aggressors were.

Table 3. Statistical analysis of dominant and submissive behaviors between females and affiliative and sexual behaviors from males to females.

\begin{tabular}{|c|c|c|c|c|}
\hline $\begin{array}{l}\text { Line } \\
\text { Nos. }\end{array}$ & & & $\begin{array}{c}\text { UD } \\
\text { (Dom vs Sub females) }\end{array}$ & $\begin{array}{c}\text { CD } \\
\text { (Dom vs Sub females) }\end{array}$ \\
\hline 1 & \multicolumn{2}{|c|}{ Dominance behaviors } & \multicolumn{2}{|c|}{ MANOVA, $F_{(1,44)}=0.172, P=0.843$} \\
\hline 2 & & Male absent & $P=0.998$ & $P=1.000$ \\
\hline 3 & \multirow[t]{2}{*}{ Tukey } & Male present & $P=0.411$ & $P=0.983$ \\
\hline 4 & & Male resident & $P=0.175$ & $P=0.999$ \\
\hline 5 & \multicolumn{2}{|c|}{ Submissive behaviors } & \multicolumn{2}{|c|}{ MANOVA, $F_{(1,20)}=2.443, P=0.129$} \\
\hline 6 & & Male absent & $P=1.000$ & $P=1.000$ \\
\hline 7 & Tukey & Male present & $P=0.228$ & $P=1.000$ \\
\hline \multirow[t]{2}{*}{8} & & Male resident & $P=0.039^{*}$ & $P=1.000$ \\
\hline & & & $\begin{array}{l}\text { UD Sub females vs } \\
\text { CD Sub females }\end{array}$ & $\begin{array}{l}\text { UD Sub females } \\
\text { vs CD Dom females }\end{array}$ \\
\hline 9 & \multicolumn{2}{|c|}{ Submissive behaviors } & \multicolumn{2}{|c|}{ MANOVA, $F_{(1,20)}=2.443, P=0.129$} \\
\hline 10 & & Male absent & $P=1.000$ & $P=1.000$ \\
\hline 11 & Tukey & Male present & $P=0.568$ & $P=0.296$ \\
\hline \multirow[t]{2}{*}{12} & & Male resident & $P=0.038^{*}$ & $P=0.047^{*}$ \\
\hline & & & $\begin{array}{l}\text { Male to UD females } \\
\text { (Dom vs Sub) }\end{array}$ & $\begin{array}{l}\text { Male to CD females } \\
\text { (Dom vs Sub) }\end{array}$ \\
\hline 13 & \multicolumn{2}{|c|}{ Affiliative behaviors } & \multicolumn{2}{|c|}{ MANOVA, $F_{(1,22)}=0.006, P=0.938$} \\
\hline 14 & Tukey & Male present & $P=0.980$ & $P=1.000$ \\
\hline \multirow[t]{2}{*}{15} & & Male resident & $P=0.936$ & $P=1.000$ \\
\hline & & & $\begin{array}{l}\text { Male to UD females } \\
\text { (Dom vs Sub) }\end{array}$ & $\begin{array}{l}\text { Male to CD females } \\
\text { (Dom vs Sub) }\end{array}$ \\
\hline 16 & \multicolumn{2}{|c|}{ Sexual behavior } & \multicolumn{2}{|c|}{ MANOVA, $F_{(1,22)}=0.354, P=0.568$} \\
\hline 17 & Tukey & Male present & $P=0.863$ & $P=0.914$ \\
\hline 18 & & Male resident & $P=0.882$ & $P=1.000$ \\
\hline
\end{tabular}


UD
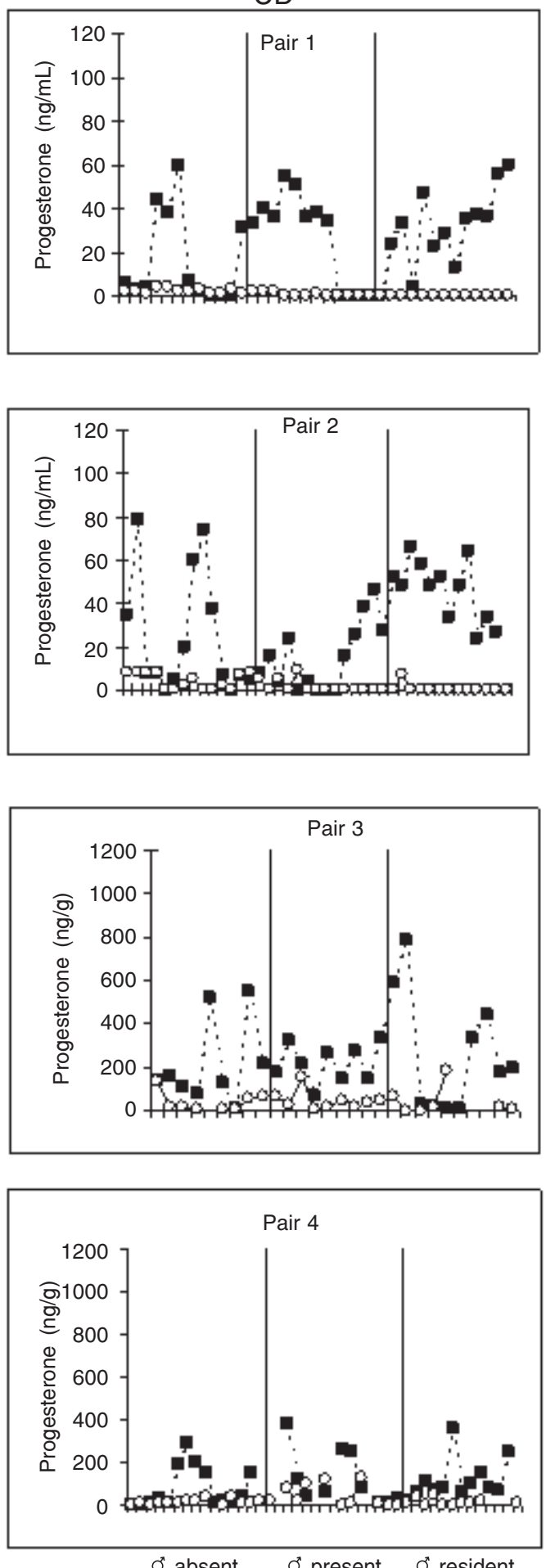
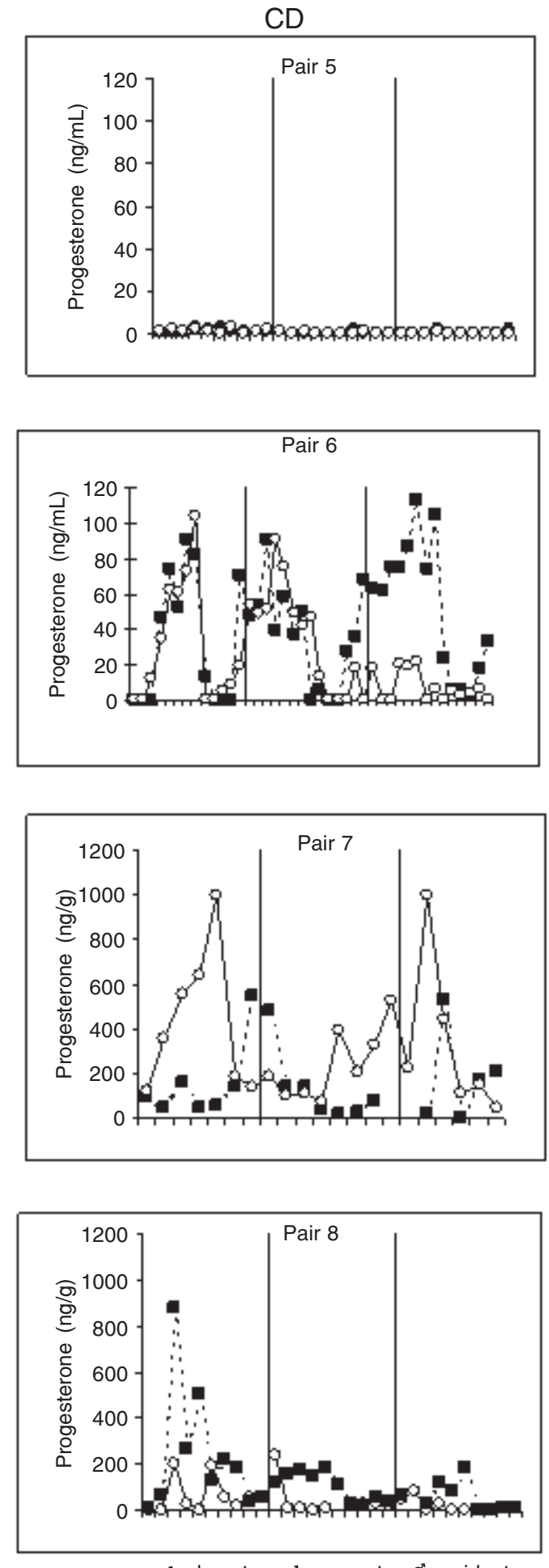

$\sigma^{*}$ absent $\sigma^{*}$ present $\sigma^{*}$ resident

Figure 3. Progesterone levels in 8 Callithrix jacchus female pairs during the three 5-week study periods. The hormone was measured in plasma $(\mathrm{ng} / \mathrm{mL})$ for pairs $1,2,5$, and 6 or in feces $(\mathrm{ng} / \mathrm{g})$ in pairs $3,4,7$, and 8 , collected twice a week. Squares indicate dominant females and circles subordinate females. Straight lines indicate the end of a 5-week period and the beginning of the next. UD = uncontested dominance; $C D=$ contested dominance. 


\section{Discussion}

We report, for the first time, the concept of CD and UD in female-female pairs of marmosets. Dominance relationships between females are not always uniform in common marmosets, especially in the presence of an unrelated male, as reported in other studies with captive (11) and wild animals (17). The relationships were more complex when there was continuing competition among females. It has been reported (5) that in non-kin captive groups comprising multiple males and females, in which at least one anovulatory subordinate female was identified, a single dominant female emerged after 2 to 3 days of co-habitation, but that does not appear to be always the case when females are related, as demonstrated in the present study. Competition for dominance may last 10 weeks or more, and subordination may not readily be accepted by about $50 \%$ of females under these circumstances.

Such long-term competition for dominance may provide an explanation for reports regarding wild-C. jacchus groups that describe either two ovulating $(32,33)$ or two breeding females (15-17,20). Contesting dominance may provide an alternative strategy for otherwise anovulatory subordinate females that remain in their native groups. Under such circumstances, to reproduce as a secondary female may be more advantageous than waiting for a dominant female vacancy in a neighboring group or opting to emigrate away from a familiar forest area (17).

Why should there be competition in some of the groups and not in others? One possible explanation is the existence of kin relations between the females. It is well known that in this species around half of the daughters ovulate when housed together with their mothers $(5,10)$. In the presence of an unrelated male, those that ovulate are not subordinate to their mothers, whereas those daughters that do not ovulate are subordinate to their mothers $(10,11)$. Of course, kinship cannot be treated apart from familiarity, and in that case, it would include the two pairs whose kin relations we do not know (34). Differing degrees of kinship, however, cannot explain the differences between the pairs of females in this study, since pairs with exactly the same kind of relatedness were classified as either UD or CD (2 pairs of twins, 1 mother and daughter pair, and 1 pair of females of unknown kinship in each grouping).

Ovulating daughters show higher levels of aggression towards their mothers only in the presence of a new, non-related male (10), suggesting that this is a critical factor for the occurrence of polygyny. But again, this factor alone cannot explain the difference observed here between UD and CD because an unrelated male was present in all pairs. Likewise, both polygyny and monogamy have been reported in wild- $L$. rosalia groups that contained an unrelated adult male (20). That same study also reported that in polygynous groups daughters apparently bred without any observed aggression from the dominant female. The authors suggest that the inclusive reproductive fitness of mothers was even increased, under some circumstances, when their daughters bred in their natal groups (20). A recent study in our field site suggested that wild-common marmoset groups could be either monogamous or polygynous and, when monogamous, subordinate females sometimes tried to breed. These attempts were always unsuccessful, and these females lost their infants and left the groups shortly after (17). On occasions, infanticide of the offspring of subordinate females would happen, and was witnessed in five separate incidents (19,35 and Arruda MF, personal communication). It is possible that dominant females in free-living $C$. jacchus groups benefit in reproductive terms from successful reproduction by a subordinate only in very specific circumstances (17), in contrast to the reports for free-living L. rosalia groups. 
The suspected infanticide observed in one of our CD pairs (pair 7) might indicate a similar strategy employed by dominant females living in captive groups.

Some of the wild-subordinate females that bred with outside males in our field site (17) became, eventually, the only breeding female in another neighboring group. It was suggested that, as proposed before (36), the availability of breeding positions is unpredictable, and subordinate females should be ready to occupy them when they occur.

Previous reports $(16,17,19)$, together with the data obtained in the present study, suggest that the occurrence of two breeding females in a $C$. jacchus group possibly requires predictable prerequisites: relatedness between females, and the reproductive and/ or behavioral stimulation of subordinate females by an unrelated male. In wild groups, that stimulation could easily arise from males in neighboring groups, since extra-group copulations involving non-breeding females have been reported for $C$. jacchus $(17,22,33)$. However, while all free-living female marmosets are exposed to such stimulation, not all free-living $C$. jacchus groups contain two breeding females (17).

It has been suggested that the occurrence of breeding by subordinates may arise from increased tolerance from dominants that allow limited breeding as a strategy to retain subordinates in their groups (37). A critique of this model suggests that subordinates breed simply because dominants are unable to prevent it (38). This seems to be the case in $C$. jacchus, as dominant females do not make an effort to retain adult daughters in their group, and also, in some instances, direct agonistic behavior to subordinate females that attempt to breed (31).

The present study does not provide any indication as to why some females may be more responsive to unrelated male stimulation than others. Our data regarding the behavior of males suggest that they do not discriminate between dominant and subordinate females from either group as the targets of affiliate and sexual behavior. Most probably, the differential response of subordinate females to the presence of a male results in some subordinate females being less willing to reliably submit to another female without contest. Despite the small sample size $(N=4)$, the evidence of this study reinforces the flexibility of the neuroendocrine functioning of the hypothalamicpituitary-ovarian axis in common marmoset females. As pointed out in the literature (39), the mechanism underlying the inhibition involves the lack of sensitivity of the pituitary to gonadotropin-releasing hormone in subordinate females, mediated by behavioral and/or pheromonal cues. However, the intrinsic mechanisms of inhibition and that of the rapid return to ovarian cyclicity in subordinate females remain to be demonstrated (40).

Reports about wild groups show that in a natural environment, reproductive competition between females may last for many months, especially when opportunities to avoid direct interaction with other group members are available (32). Reports from our field site have demonstrated two females breeding simultaneously in the same group over a period ranging from many months to up to 4 years (17) in three separate groups, suggesting that wild conditions may be more favorable for the expression of contested dominance. Furthermore, under natural conditions many factors interfere with the breeding success of dominant and subordinate females, and they all probably influence the decisions regarding reproductive strategies for both dominant and subordinate females, as reported for L. rosalia (20). A closer examination of these conditions for wild $C$. jacchus is necessary for a better understanding of the costs and benefits of different reproductive strategies for dominant and subordinate females. 


\section{Acknowledgments}

The authors wish to thank Guenther Scheffler, National Primate Research Center of the University of Wisconsin-Madison (WPRC), for kindly permitting the analysis of blood samples in the Assay Services Labo- ratories, Antônio B. da Silva and Edinólia Câmara for assisting with the care of the animals, Fívia A. Lopes, Marcelina S. Oliveira and Geylson O. França for helping with data collection, and Maja F.B. Veloso and Michelle S. Cunha for the assessment of fecal samples.

\section{References}

1. Liska J (1990). Dominance-seeking strategies in primates: an evolutionary perspective. Journal of Human Evolution, 5: 75-90.

2. Cheney DL \& Seyfarth RM (1987). How Monkeys See the World. Chicago University Press, Chicago, IL, USA.

3. Harding RSO (1980). Agonism, ranking and social behavior of adult male baboons. American Journal of Physical Anthropology, 55: 203216.

4. Clarke MR, Kaplan JR, Bumsted PT et al. (1986). Social dominance and serum testosterone concentration in dyads of male Macaca fascicularis. Journal of Medical Primatology, 15: 419-432.

5. Abbott DH \& Hearn JP (1978). Physical, hormonal and behavioral aspects of sexual development in marmoset monkey, Callithrix jacchus. Journal of Reproduction and Fertility, 53: 155-166.

6. Heistermann M, Kleis E, Prove E et al. (1989). Fertility status, dominance, and scent marking behavior of family-housed female cotton-top tamarins (Saguinus oedipus) in absence of their mothers. American Journal of Primatology, 18: 177-189.

7. Epple G \& Katz Y (1984). Social influences on estrogen excretion and ovarian cyclicity in saddle-back tamarins (Saguinus fuscicollis). American Journal of Primatology, 6: 215-228.

8. Ziegler TE, Savage A, Scheffler G et al. (1987). The endocrinology of puberty and reproductive functioning in female cotton-top tamarins (Saguinus oedipus) under varying social conditions. Biology of Reproduction, 37: 618-627.

9. Abbott DH, McNeilly AS, Lunn SF et al. (1981). Inhibition of ovarian function in subordinate female marmoset monkeys (Callithrix jacchus jacchus). Journal of Reproduction and Fertility, 63: 335-345.

10. Saltzman W, Severin JM, Schultz-Darken NJ et al. (1997). Behavioral and social correlates of escape from suppression of ovulation in female common marmosets housed with the natal family. American Journal of Primatology, 41: 1-21.

11. Saltzman W, Schultz-Darken NJ \& Abbott DH (1997). Familial influences on ovulatory function in common marmoset (Callithrix jacchus). American Journal of Primatology, 41: 159-177.

12. Abbott DH (1993). Social conflict and reproductive suppression in marmoset and tamarin monkeys. In: Mason WA \& Mendoza SP (Editors), Primate Social Conflict. SUNY Press, Albany, NY, USA.

13. Hubrecht RC (1989). The fertility of daughters in common marmoset (Callithrix jacchus jacchus) family groups. Primates, 30: 423-432.

14. Rothe H \& Koenig A (1991). Variability of social organization in captive common marmosets (Callithrix jacchus). Folia Primatologica, 57: 28-33.

15. Scanlon CE, Chalmers NR \& Monteiro da Cruz MAO (1988). Changes in the size, composition and reproduction conditions of wild marmoset groups (Callithrix jacchus jacchus) in northeast Brazil. Primates, 29: 295-305.

16. Digby LJ \& Ferrari SF (1994). Multiple breeding in free-ranging groups of Callithrix jacchus. International Journal of Primatology, 3 : 389-397.

17. Arruda MF, Araújo A, Sousa MBC et al. (2005). Two-breeding females within free-living groups may not always indicate polygyny: Alternative subordinate female strategies in common marmosets (Callithrix jacchus). Folia Primatologica, 76: 10-20.

18. Goldizen AW, Mandelson J, van Vlaadingen M et al. (1996). Saddleback tamarins (Saguinus fuscicolis) reproductive strategies: Evidence from a thirteen-year study of a marked population. American Journal of Primatology, 38: 57-83.

19. Digby LJ (1995). Infant care, infanticide, and female reproductive strategies in polygynous groups of common marmosets (Callithrix jacchus). Behavioral Ecology and Sociobiology, 37: 51-61.

20. Dietz JM \& Baker AJ (1993). Polygyny and female reproductive success in golden lion tamarins, Leontopithecus rosalia. Animal Behavior, 46: 1067-1078.

21. Arruda MF, Yamamoto ME \& Bueno OFA (1986). Interactions between parents and infants and infants/father separation in the common marmoset (Callithrix jacchus). Primates, 27: 215-228.

22. Lazaro-Perea C, Castro CSS, Harrison R et al. (2000). Behavioral and demographic changes following the loss of the breeding female in cooperatively breeding marmosets. Behavioral Ecology and Sociobiology, 48: 137-146.

23. Rothe H (1975). Some aspects of sexuality and reproduction in groups of captive marmosets (Callithrix jacchus). Zeitschrift für Tierpsychologie, 37: 255-273.

24. Saltzman W, Pick RR, Salper OJ et al. (2004). Onset of plural cooperative breeding in common marmoset families following replacement of the breeding male. Animal Behavior, 68: 59-73.

25. Harlow CRS, Hodges JK \& Hearn JP (1983). The relationship between plasma progesterone and timing of ovulation and early embryonic development in marmoset monkey (Callithrix jacchus). Journal of Zoology, 201: 273-282.

26. Munro C \& Stabenfeldt G (1984). Development of microtitre plate enzyme immunoassay for the determination of progesterone. Journal of Endocrinology, 101: 41-40.

27. Ziegler TE, Scheffler G, Wittwer DJ et al. (1996). Metabolism of reproductive steroids during the ovarian cycle in two species of callithrichids, Saguinus oedipus and Callithrix jacchus, and estimation of ovulatory period from fecal steroids. Biology of Reproduction, 54: 91-99.

28. Saltzman W, Schultz-Darken NJ, Sheffler G et al. (1994). Social and reproductive influences on plasma cortisol in female marmoset monkeys. Physiology and Behavior, 56: 801-810.

29. Sousa MBC \& Ziegler TE (1998). Diurnal variation on the excretion patterns of steroids in common marmoset (Callithrix jacchus) females. American Journal of Primatology, 46: 105-117. 
30. Ziegler TE \& Sousa MBC (2002). Parent-daughter relationships and social controls on fertility in female common marmosets, Callithrix jacchus. Hormones and Behavior, 42: 356-367.

31. Saltzman W, Schultz-Darken NJ, Wegner FH et al. (1998). Suppression of cortisol levels in subordinate female marmosets: reproductive and social contributions. Hormones and Behavior, 33: 58-74.

32. Albuquerque ACSR (2003). Estratégias reprodutivas de fêmeas de Callithrix jacchus em grupos poligínicos e monogâmicos no ambiente natural. Doctoral thesis, Departamento de Fisiologia, Universidade Federal do Rio Grande do Norte, Natal, RN, Brazil.

33. Albuquerque ACSR, Sousa MBC, Santos HM et al. (2001). Behavioral and hormonal analysis of social relationship between oldest females in wild monogamous groups of common marmoset, Callithrix jacchus. International Journal of Primatology, 22: 631-645.

34. Porter RH (1990). Littermate influences on behavioral and physiological development in spiny mice. In: Dewsbury DA (Editor), Contemporary Issues in Comparative Psychology. Sinauer Press, Sunderland, MA, USA.

35. Arruda MF, Albuquerque FS \& Miranda RQ (1994). Registro de infanticídio em um grupo poligínico de Callithrix jacchus no ambiente natural. XII Encontro Anual de Etologia 1994, Cananéia, SP, Brazil, October 6-8, 157-158.

36. Emlen ST (1991). Evolution of cooperative breeding in birds and mammals. In: Krebs JR \& Davies NB (Editors), Behavioral Ecology. Blackwell, Oxford, UK.

37. Emlen ST, Reeve HK \& Keller L (1998). Reproductive skew: disentangling concessions from control. Trends in Ecology and Evolution, 13: 458-459.

38. Clutton-Brock TH (1998). Reproductive skew, concessions and limited control. Trends in Ecology and Evolution, 13: 288-292.

39. Abbott DH, George LM, Barret J et al. (1990). Social control of ovulation in marmoset monkeys: A neuroendocrine basis for the study of fertility. In: Ziegler TE \& Bercovitch FB (Editors), Socioendocrinology of Primate Reproduction. Wiley-Liss, New York.

40. Abbott DH, Saltzman W, Schultz-Darken NJ et al. (1998). Adaptations to subordinate status in female marmoset monkeys. Comparative Biochemistry and Physiology, 119: 261-274. 